\title{
PLANO ESTADUAL DE EDUCAÇÃO PERMANENTE EM SAÚDE: UM COMO FAZER COM BASE NO NORDESTE BRASILEIRO
}

PUBLIC POLICY FOR PERMANENT EDUCATION IN HEALTH: A HOW-TO FOR THE BRAZILIAN NORTHEAST

POLÍtica PÚBLICA DE EDUCACIÓN PERMANENTE EN SALUd: Un CÓMO HACERLO BASAdO EN EL NORESTE BRASILEÑO

Ricardo Burg Ceccim

Silvia Maria Negreiros Bomfim Silva ${ }^{2}$

Luis Fernando de Souza Benício ${ }^{3}$

Kilvia Paula Soares Macedo 4

Cândido Sampaio de Castro Neto ${ }^{5}$

Karina Oliveira de Mesquita 6

José Luís Paiva de Mendonça Ferreira 7

Ívina Maria Siqueira Lima 8

Como Citar:
Ceccim RB, Silva SM, Benício

LF, Macedo KP, Castro Neto CS, Mesquita KO, et al. Plano Estadual de Educação Permanente em Saúde: um como fazer com base no Nordeste brasileiro. Sanare (Sobral, Online). 2021;20(1):142-152.

Palavras-chave:

Pessoal de Saúde; Apoio ao Desenvolvimento de Recursos Humanos; Aprendizagem; Educação em Saúde; Educação Permanente.

Keywords:

Health Personnel; Training Support; Learning; Health Education; Education, Continuing.

Palabras clave:

Personal de Salud; Apoyo a La Formación Profesional; Aprendizaje;

Educación en Salud; Educación Continua.

Submetido: $16 / 12 / 2020$

Aprovado: $17 / 06 / 2021$

Autor(a) para Correspondência: Ricardo Burg Ceccim E-mail: burgceccim@gmail.com

\section{RESUMO}

No Estado do Ceará, Nordeste brasileiro, em 2018, foi empreendida uma pesquisa-formação acoplada ao planejamento participativo em saúde que escutou e analisou realidades locais mediante oficinas locorregionais. 0 objetivo foi a escuta e a análise problematizadoras (pesquisa-formação) e a formulação de um projeto de intervenção como política pública (planejamento participativo). Da pesquisa, emergiu a compreensão de um particular conceito de saúde, próprio à região do semiárido nordestino, "saúde cabra da peste", que veio como saúde do cuidado em família, diferente do propalado conceito de saúde da família. A presença da Educação Popular como transversal às práticas de cuidado e a noção de território como centro, vieram inovadoras, não com o paroquialismo frequente nos discursos sobre saúde da família, mas como presença do "lugar" (adaptação ao global, mas também resistência local). Também foi evidente a presença de estudantes e universidades nas realidades locais, especialmente pelo interior. O planejamento se concluiu com seis eixos estratégicos, em que a atenção e a gestão da clínica vieram, não como carro-chefe, mas sucedâneas a uma estrutura de desenvolvimento do sistema e do trabalho em saúde. Como ganho e produto final, tem-se a emergência de um "como fazer", que contempla pesquisa, formação, intervenção e gestão de política pública.

1. Sanitarista. Mestre em Educação. Doutor em Psicologia Clínica. Professor Titular na Universidade Federal do Rio Grande do Sul, Programa de Pós-Graduação em Educação. E-mail: burgceccim@gmail.com. ORCID: https://orcid. org/0000-0003-0379-7310

2. Administradora (Saúde). Mestre e Doutoranda em Planejamento Urbano e Regional. Professora da Faculdade de Tecnologia de Horizonte, Ceará. E-mail: silvianegreiros@uol.com.br. ORCID: https://orcid.org/0000-0001-5835$\underline{3229}$

3. Psicólogo. Mestre e Doutorando em Psicologia. Professor Substituto na Universidade Estadual do Ceará. E-mail: luisf.benicio@gmail.com.0RCID: https://orcid.org/0000-0002-0765-2568

4. Enfermeira. Mestre e Doutoranda em Cuidados Clínicos em Enfermagem e Saúde. E-mail: kilviapsmacedo@gmail. com. ORCID: https://orcid.org/0000-0001-5976-9883

5. Fisioterapeuta. Mestre em Saúde da Criança e do Adolescente. Consultor na Região Sertão Central da Secretaria da Saúde do Estado do Ceará. E-mail: candidofisio@hotmail.com. ORCID: https://orcid.org/0000-0003-1482-1646 6. Enfermeira. Mestre em Saúde da Família. Docente na Escola de Saúde Pública Visconde de Saboia, Sobral. E-mail: karinamesquita1991@gmail.com.0RCID: https://orcid.org/0000-0003-1528-5339

7. Fisioterapeuta. Mestre em Gestão em Saúde. Assessor Técnico na Escola de Saúde Pública do Ceará. E-mail: joseluispaiva01@gmail.com.0RCID: https://orcid.org/0000-0002-0466-3747

8. Enfermeira. Especialista em Gestão de Sistemas Locais de Saúde. Mestre em Ensino na Saúde. Assessora Técnica na Escola de Saúde Pública do Ceará. E-mail: ivina.siqueira.esp@gmail.com. 0RCID: https://orcid.ora/0000-0003$\underline{4633-6020}$

Cert. de Redação Científica: Central das Revisões. Edição de texto: Karina Maria M. Machado. Revisão de provas: Texto definitivo validado pelos (as) autores (as). 


\section{ABSTRACT}

In 2018, in the state of Ceará in the Brazilian north-east, a research-training took place coupled with participative health planning, that listened and then analyzed local realities through local-regional workshops. The goals were of a problematizer listening and analysis (research-training) and the shaping of an intervention project as public policy (participative planning). The research resulted in the understanding of a specific health concept pertaining to the semi-arid north-eastern region - "cabra da peste" health - health as care in family, which differs from the renowned concept of family health. The innovation came with Popular Education intersected by care practices, and the notion of the territory as center; not with the frequent parochialism in discourses about family health, but as the presence of place (adaptation to the global, but also local resistance). There was also the evident presence of universities and students in local realities, especially in the countryside. Planning resulted in six strategic axes, where health care and clinical management came not as flagship programs but as the result of the developmental structure of working with health and the health system. The positive final product, a "how-to", was reached, contemplating research, training, intervention, and public policy management.

\section{RESUMEN}

En el estado de Ceará, noreste brasileño, en 2018, se emprendió una investigación-formación acoplada a la planificación participativa en salud que escuchó y analizó realidades locales mediante talleres locoregionales. El objetivo fue la escucha e el análisis problematizadores (investigación-formación) y la formulación de un proyecto de intervención como política pública (planificación participativa). De ello emergió la comprensión de un particular concepto de salud, propio al semiárido nordestino - salud "cabra da peste" - utilizado en lugar del difundido concepto de salud de la familia. La presencia de la Educación Popular como transversal a las prácticas de cuidado y la noción de territorio como centro, son innovadoras, no con el parroqualismo frecuente en los discursos sobre salud de la familia, sino como presencia del lugar, adaptación al global y resistencia local. Además, hay evidencias de la presencia de estudiantes y universidades en las realidades locales, especialmente en el interior. La planificación se concluyó con seis ejes estratégicos, en que la atención y la gestión de la clínica vinieron no como centrales, sino análogas a una estructura de desarrollo del sistema y del trabajo en salud. Como ganancia y producto final, la emergencia de un "cómo hacerlo" que abarca investigación, formación, intervención y gestión de política pública.

\section{INTRODUÇÃO}

Em 2017, o Governo Federal lançou o "Programa para o Fortalecimento das Práticas de Educação Permanente em Saúde" no sistema sanitário brasileiro (Pró-EPS/SUS) ${ }^{1,2}$, tendo como objetivo estimular, acompanhar e fortalecer a qualificação profissional em direção ao atendimento dos princípios fundamentais do Sistema Único de Saúde (SUS). Diante disso, no Estado do Ceará, região Nordeste do Brasil, foi montada uma estratégia de construção do Plano Estadual de Educação Permanente em Saúde em que as propostas fossem pautadas pela escuta e pela análise das realidades locais $^{3}$, priorizando o fortalecimento da regionalização, o pensamento das redes e a incorporação do aprender ao cotidiano do trabalho.
Esse desenho foi resultado da iniciativa de acoplar - planejamento participativo em saúde ${ }^{4}$ e a pesquisa-formação por círculos em rede ${ }^{5}$. No correr do processo, impuseram-se a educação popular em saúde e a linguagem do acesso, acolhimento e vínculo com os usuários da atenção básica, assim como uma particular linguagem das ligas acadêmicas e da universidade presente na cidadania. 0 Plano foi elaborado ao longo do ano de 2018, finalizado e aprovado na última reunião do Conselho Estadual de Saúde (CESAU) daquele ano, na última plenária de dezembro.

Um grupo de estudos foi reunido em 2018, pela Escola de Saúde Pública, em torno da temática da integração ensino-serviço em saúde, para que acompanhasse a elaboração do Plano mediante a metodologia da pesquisa-formação por círculos 
em rede ${ }^{5}$. Um plano é uma prospecção de futuros, um delineamento de expectativas. Desse modo, o planejamento participativo em saúde pode ser um instrumento, uma tecnologia ou uma metodologia, mas, daqueles que trabalham no campo sanitário, espera-se que agregue crescente autonomia e protagonismo de usuários, trabalhadores e gestores junto ao sistema de saúde ${ }^{4}$.

A pesquisa-formação se configura na medida em que se articula a interatividade pesquisadorespesquisados e se enseja a aprendizagem significativa pela presença dos/com os/nos cotidianos, em que os encontros de pesquisa são também encontros de formação ${ }^{6}$. 0 produto alcançado, entretanto, vem aqui sumarizado por meio da Análise Documental, uma vez que, recuperado a posteriori e para fins de difusão, permite encontrar restos, marcas e vestígios no tempo e no espaço, não se tratando de buscar uma prova e sim uma pista de que algo ocorreu, tampouco restituir uma totalidade histórica, mas colocar em narrativa uma articulação do presente com o passado, justificando-se também como dispositivo de memória ${ }^{7}$.

No Ceará, Programas como Saúde da Família e Agentes Comunitários de Saúde têm inserção desde os anos 1980, e a Estratégia Saúde da Família desde 1994. Iniciativas que, no Brasil, têm sido reportadas à modelagem tecnoassistencial sugerida à Atenção Básica ${ }^{8}$. Desde a primeira edição de uma Política Nacional de Atenção Básica, em 2006, projeta-se esse perfil de experiências como modelagem substitutiva e de reorganização da atenção à saúde. 0 s anos 2000 estiveram fortemente marcados pela expansão da proposta designada por Estratégia Saúde da Família, incluindo os grandes centros urbanos, em que pese ter perseverado em muitas regiões do país a falta de médicos e outros profissionais, como é o caso da Região Nordeste, especialmente do sertão nordestino ${ }^{9}$.

Todavia, na configuração da modelagem assistencial cearense, há uma bagagem cultural que vem como experiência do lugar $^{10}$. A noção de lugar, conforme Milton Santos, corresponde à noção de território vivo e dinâmico no qual se desenrola a vida. 0 lugar, nesse caso, traz as dimensões da agroecologia e da pecuária do semiárido brasileiro, da economia solidária e humana. É essa noção de Nordeste e essa noção de território que, nessa região, dá nome ao cuidado em saúde como "saúde do cuidado em família", região cuja subsistência tem base na agricultura familiar, na criação familiar de caprinos e ovinos e em uma estrutura fundiária onde predominam as pequenas propriedades de base familiar ${ }^{11}$. A pesquisa-formação encontrou na palavra família uma construção particular, expressão da vida no lugar.

Uma saúde do cuidado em família se reporta ao cuidado às pessoas ou grupos sociais que, independentemente de relações de parentesco, coabitam uma moradia ou um pátio, condividem um conjunto de estratégias de sobrevivência e compartilham práticas culturais e contexto social, a articulação de recursos institucionais e comunitários e o agenciamento do cuidado em saúde com as redes sociotécnicas. Nessa modelagem, o território (ou o lugar) é o centro da geração de práticas cuidadoras.

0 presente artigo traz a Educação Permanente em Saúde (EPS) como parte estruturante da introdução e expansão das características nordestinas que conquistaram um perfil tecnoassistencial à atenção básica com a imagem da saúde do cuidado em família, apoiando-se na sabedoria da Educação Popular, na valorização das redes e territórios de encontro e nas lutas que conduzem à valorização da vida local e fazem das culturas tradicionais a força propulsora de uma saúde que ampara e quer a vida forte e criadora de mais vida. Dito isso, o poeta cearense Patativa do Assaré, em "Cabra da Peste, faz ver a saúde como afirmação da vida:

Eu sou de uma terra que o povo padece, mas não esmorece e procura vencer. Da terra querida, que a linda cabocla, com riso na boca zomba no sofrer. Não nego meu sangue, não nego meu nome. Olho para a fome, pergunto: o que há? Eu sou brasileiro, fio do Nordeste, sou Cabra da Peste, sou do Ceará12.

A metodologia da pesquisa-formação acoplada ao planejamento participativo em saúde singularizou a construção do plano estadual de educação permanente em saúde no Ceará. Uma pesquisa de base documental revelou a elaboração do Plano como um processo ascendente e participativo, superando práticas comuns nesse tipo de atividade, abandonando a prática da elaboração de listas de cursos, vazias de sentidos e pessoas ${ }^{13}$. Não só foi construído um plano para prestar contas da tarefa prescrita pelo Governo Federal junto ao Pró-EPS/ SUS, mas operada uma ação de pensamento, não um planejar estratégico, mas um pensar a ação política em saúde, como na orientação de Mário Testa ${ }^{14}$. 
Fortalecer a EPS não se apresentou como ação programática, mas como ação educativa.

0 objetivo foi a escuta e a análise problematizadoras (pesquisa-formação) e a formulação de um projeto de intervenção como política pública (planejamento participativo). 0 objetivo da pesquisa-formação acoplada ao planejamento participativo em saúde envolveu, então, escutar e analisar realidades locais mediante oficinas locorregionais em busca do quadrilátero da formação e da educação permanente em saúde.

\section{A SAÚdE DO LUGAR, O QUADRILÁTERO DA FORMAÇÃO E A EDUCAÇÃO PERMANENTE EM SAÚDE}

o Sistema Único de Saúde, no Estado do Ceará, tem uma construção histórica particular. Tem bagagem na Educação Popular, na atuação de agentes comunitários e na implicação com as culturas tradicionais, o que conduz à valorização da vida local, dos territórios de encontro e das sensiveis lutas pela vida. Essas características conquistaram um perfil tecnoassistencial à atenção básica com a imagem da saúde em família (saúde com as práticas da cultura, saúde com as variações linguísticas e culturais do Nordeste, saúde "cabra da peste"). Na medida em que a Atenção Básica se impôs como política nacional de proteção à saúde para dar conta da população, sensível aos seus diversos grupos populacionais locais, essas delicadezas da imagem de uma saúde em convívio ganharam o lugar de informação à gestão. A "vida que vinga" não vinga apenas porque suas doenças e motivos de morte são conhecidos, vinga porque a vida e o viver valem a pena ${ }^{15}$. É apenas no interior de uma vida que vale a pena que interessa conhecer adoecimentos e morrimentos. Quando as forças de vida minguam, toda vida morre; quando as forças de vida vingam, a saúde é o que a ampara.

0 Brasil construiu, aos poucos, a posição da Atenção Básica como ordenadora e impulsionadora do sistema sanitário, introduzindo a noção de Redes de Atenção à Saúde ${ }^{16,17}$ como estratégia para superar a fragmentação entre as ações e os serviços para as diversas necessidades e para os diversos grupos populacionais, assim como a noção de Regiões de Saúde ${ }^{17}$, tendo em vista aperfeiçoar a institucionalidade política e gerencial do Sistema. Redes e Regiões deveriam assegurar, então, a descentralização da gestão, a integralidade da atenção e a abertura para a participação.

Assegurar ao usuário o conjunto de ações e serviços de que necessita, com efetividade e eficiência, entretanto, requer o desenvolvimento e a apropriação de conhecimento, o que implica educação (ensino, aprendizado e mutação ${ }^{18}$ ) e pesquisa (investigação, produção e inovação $0^{19}$ ). Descentralização da gestão, integralidade da atenção e abertura para a participação são diretrizes constitucionais do SUS. Esse "triângulo", entretanto, mostra-se limitado sem a introdução desse quarto ângulo: educação e pesquisa na saúde. Na política nacional, esse quarto ângulo ficou conhecido como Política Nacional de Educação Permanente em Saúde ${ }^{20}$. Na saúde, sem permanente educação, não acontece consistente territorialização: o aprender é da ordem vital do fazer e da experiência. Aprender é agir em construção provisória de si e dos entornos, sempre em relação a processos de encontro. Aprender é sempre sair de um lugar dado e construir outro sob invenção/criação afetiva.

A oferta de ações ou a formulação de políticas que visam acoplar o ensino-aprendizagem à realidade vivida pelos sistemas e serviços de saúde, tendo os problemas enfrentados no cotidiano do trabalho e as experiências dos trabalhadores como base de interrogação e mudança, compõem a educação permanente em saúde. Contudo, a EPS também diz respeito à integração ensino-serviçocomunidade proposta às instituições educacionais para a formação dos novos quadros profissionais requeridos e para a qualificação da docência. Diante desse desafio, a EPS, como política, enseja um esforço de elaboração participativa, envolvendo negociação e pactuação com os segmentos da gestão, dos serviços (clínica e gestão da clínica), das instituições de ensino e das instâncias de controle social via Comissões de Integração EnsinoServiço em Saúde (CIES) ${ }^{21}$.

\section{UM COMO FAZER MEDIANTE PLANEJAMENTO PARTICIPATIVO E PESQUISA-FORMAÇÃO}

A pesquisa-formação foi uma tarefa da Escola de Saúde Pública, enquanto o planejamento participativo foi uma tarefa da Coordenadoria de Gestão da Educação Permanente em Saúde, estrutura 
responsável pela valorização, educação e negociação do trabalho, junto à Secretaria de Estado da Saúde. No presente documento de escrita, apresenta-se de modo descritivo o produto conceitual alcançado no Pró-EPS/SUS para o Estado do Ceará.A Análise Documental foi um método relevante por agregar conteúdo às informações de pesquisa e normativas. 0 presente documento cumpre o papel de resgatar a memória - do percurso ao resultado - considerando o pertencimento dos autores à pesquisa-formação. 0 processo iniciou com a leitura e organização dos documentos essenciais para descrever o objeto. À medida que as informações eram organizadas em linha do tempo, foram sendo concatenadas as conexões para a melhor apreensão do processo desencadeado e do produto alcançado. A primeira fonte de análise foi o próprio Plano e documentos que fomentaram normativa e financeiramente sua produção. A cronologia começa com a Nota Técnica Conjunta 22 , de 1\%/12/2017, entre Coordenadoria de Gestão da Educação Permanente em Saúde, Conselho Estadual das Secretarias Municipais de Saúde e CIES Estadual, relativa à adesão do Estado ao Pró-EPS/SUS, e finaliza com a Ata de aprovação no CESAU (13/12/2018), e a Resolução n. ${ }^{0} 188 / 2018^{23}$, de pactuação na Comissão Intergestores Bipartite (CIB - 14/12/2018).

A construção do Plano envolveu a CIES Estadual e cinco CIES macrorregionais. As CIES são instâncias intersetoriais e interinstitucionais permanentes que participam da formulação, condução e desenvolvimento da política de educação na saúde ${ }^{21}$. As CIES foram o cenário para as discussões e elaboração do Plano, de modo que cada uma contou com a participação de um bolsista de pesquisa, selecionado por conhecimentos formais ligados à EPS, com formação de mestrado ou mestrandos, e um consultor doutor para a orientação metodológica. É essencial destacar que quando iniciaram as discussões acerca do Plano só havia três CIES instituídas, além da Estadual: Fortaleza, Cariri e Sobral. As outras duas, Sertão Central e Litoral Leste/Jaguaribe, foram instituídas durante o movimento de elaboração e discussão do Plano.

A elaboração do Plano foi discutida, primeiramente, em plenária, durante reunião extraordinária da CIES Estadual, realizada em 18/04/2018. 0 primeiro movimento foi a deliberação pela construção por Eixos, o que daria estrutura de intervenção à pesquisa-formação.
Tais eixos deveriam evidenciar uma política de educação na saúde, não um programa de ensino. Portanto, supunham a criação ou fortalecimento de instâncias; desenvolvimento ou implantação de estruturas permanentes de formação; construção de competências de gestão, de ensino e de atenção; familiarização com tecnologias científicas, populares e participativas; e ativação de práticas colaborativas em serviços e intersetoriais.

Foram pactuados, naquele momento, cinco grandes eixos: Construção e consolidação do Sistema de Saúde Escola; Incentivo ao desenvolvimento científico e tecnológico; Contribuição às inovações metodológicas de educação na saúde; Participação no desenvolvimento de gestores e lideranças no SUS; e Fortalecimento da integração ensino-serviço. Foi no correr das oficinas regionais que emergiu um sexto eixo: Desenvolvimento e aperfeiçoamento da Atenção Integral à Saúde. Chama atenção, conforme descrito no documento de apresentação ao CESAU, a inversão dos processos anteriores que se esgotavam exatamente neste último eixo, dessa vez emergente apenas ao longo das sistematizações do processo e que, segundo foi declarado, enunciava o esforço de uma estratégia estruturante de sustentabilidade regionalizada, em arquitetura de redes e em aprendizagem incorporada aos cotidianos de uma saúde do lugar, não a lista de cursos, elencada apenas na reunião das áreas técnicas da Secretaria de Estado da Saúde (o que merece tematização específica em outro documento de escrita, pois a pesquisa-formação identificou como a necessidade de formação de formuladores).

As noções de planejamento participativo e pesquisa-formação se acoplaram de modo inédito. 0 percurso escolhido foi o de oficinas regionais e oficinas temáticas, que teceram o aprofundamento dos eixos. Foram realizadas dez oficinas regionais, sendo duas em cada macrorregião, cinco oficinas temáticas e uma última de consolidação do Plano com a CIES Estadual. 0s pesquisadores tiveram papel fundamental na articulação dos representantes do quadrilátero $0^{4,24}$ em cada região e na organização da representação dos gestores municipais, participando em momentos das Comissões Intergestores Regionais (CIR). A primeira oficina em cada região serviu à identificação de conhecimentos e práticas vigentes, servindo à intervenção da pesquisaformação como círculo regional, e à elaboração de propostas para a constituição do Plano. A segunda oficina operava a ação crítico-colaborativa da 
pesquisa-formação e a qualificação da minuta de Plano. Já com a contribuição de todas as regiões, a segunda oficina colocava os círculos em rede, como previsto na metodologia de pesquisa-formação por círculos em rede 5 . Todas as regiões puderam problematizar e qualificar a minuta, atendendo aos requisitos teórico-metodológicos do planejamento participativo.

Cada oficina da $1^{\text {a }}$ Etapa foi organizada em quatro momentos: 1) acolhimento, promovido pela própria região, e apresentação da estratégia de desenvolvimento do Plano; 2) apresentação referencial dos eixos, apresentação do cenário macrorregional de educação na saúde, demonstrando as potencialidades, dificuldades e demandas represadas de formação; 3 ) grupos de trabalho para debulhar e circunscrever os eixos do plano, respondendo: nos sentimos representados nessa proposta do Plano? 0 que sugerimos? Quais as maiores potências da nossa macrorregião? Quais os maiores desafios/dificuldades da nossa macrorregião? 4) plenária para a apresentação dos grupos e providência de uma leitura de síntese por observador especialista.

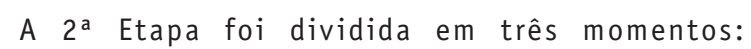
1) acolhida pela região, com apresentação do andamento da construção coletiva do Plano; 2) apresentação da análise de situação de saúde da macrorregião; 3) grupo de trabalho com os seguintes questionamentos: quais sugestões e alterações você faria no Plano; que estratégias podem ser pensadas para articular o Plano Estadual com os Planos Municipais? 4) plenária e síntese.

A regionalização orientou a sistematização dos dados e os processos de negociação e pactuação entre os gestores (CIES Regionais), contribuindo à gestão solidária entre os gestores locorregionais e entre esses e o gestor estadual. Cada etapa macrorregional foi capaz de mobilizar olhares, ouvidos e práticas de trabalhadores, gestores, docentes, estudantes, residentes em saúde, educadores populares e movimentos sociais.

\section{UM PLANO ESTADUAL DE EDUCAÇÃO PERMANENTE EM SAÚDE NO TERRITÓRIO NORDESTINO}

A Portaria GM n. ${ }^{0} 4.279^{16}$, de 30 de dezembro de 2010, diz que Redes de Atenção à Saúde têm por objetivo promover a integração de ações e serviços sanitários no âmbito do território e que devem prover uma atenção contínua, integral, de qualidade e humanizada, construindo um sistema integrado de saúde, articulado em todos os âmbitos do cuidado. A Atenção Básica tem na Estratégia Saúde da Família (ESF) a modelagem prioritária para seu arranjo organizativo de ações e serviços no âmbito das unidades básicas de saúde. A partir da implantação da ESF ${ }^{25}$, como desafio nacional, foi possivel melhor distribuir e provisionar equipes locais de cuidado individual e coletivo, o que repercutiu em melhoria da cobertura e da qualidade da atenção pré-natal e de puericultura, com consequente redução da mortalidade infantil, assim como a ampliação do acesso a serviços de saúde para populações vulnerabilizadas pelas desigualdades sociais de nosso país.

A ESF, como pauta às Redes de Atenção, ponto obrigatório nas Linhas de Cuidado e requerimento à colaboração interprofissional ${ }^{26}$, levou à reorganização das ações de promoção, prevenção, tratamento e reabilitação a que os sistemas tradicionais de ensino e de trabalho na saúde estavam acostumados, colocando em evidência a formação de trabalhadores, mas também de gestores e de docentes. Se a ESF implicou a redução de internações por condições sensiveis à Atenção Básica, há necessidade, entretanto, de ampliar a capacidade de resposta das equipes de Saúde da Família (eSF) frente aos agravos que surgem e ressurgem no Brasili27.

Quando foi lançado no país o Programa de Requalificação das Unidades Básicas de Saúdee, com o objetivo de melhorar a infraestrutura da rede de serviços e prover as condições mais adequadas para o seu funcionamento, assim como melhorar o acesso à atenção básica e a qualidade da atenção prestada, tudo isso englobou ampliação de unidades, estruturação tecnológica e qualificação das equipes multiprofissionais. A ampliação da qualidade e da resolutividade da Saúde da Família requer também o recurso às tecnologias de informação e comunicação remotas (meio digital), com a finalidade de que os serviços contem, mesmo na distância, com acesso ao conhecimento de que necessitam, isto é, incorporar sistemas de telessaúde, segundo suas atividades educacionais de tele-educação, teleconsultoria, telediagnóstico e segunda opinião formativa.

A noção de lugar aparece sem qualquer perspectiva paroquialista, o local não pode ignorar 
visões e interesses mais vastos e abrangentes. 0 lugar se mostra como expressão de resistência, mas ao mesmo tempo de adaptação à ordem global29. Obtêm-se consciência e presença de mundo, segundo se estabeleça o domínio e a apropriação do local. Longe da homogeneização do local, a noção de lugar reforça a diferenciação e as especificidades locais, sem se desvincular da ordem global. Tratase de uma singularização que incide no global, constituindo força viva ou de território vivo. Por isso, é a saúde do/no lugar, é a saúde cabra da peste que passa a informar o Plano Cearense, não mais o "Plano Estadual de Educação Permanente em Saúde do Ceará", mas o Plano Cearense de Educação Permanente em Saúde ${ }^{13}$. Foi o que descobriu a pesquisa-formação no confronto pesquisadorespesquisados, na escuta e análise emergentes da pesquisa-formação por círculos em redes.

\section{O PLANO COMO PRODUTO}

A $1^{\text {a }}$ Etapa envolveu 375 participantes, enquanto

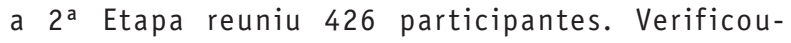
se nos dois movimentos a desnaturalização do Plano pelo processo participativo e de pesquisa: a emergência de um sexto eixo não existente na pactuação inicial, a singularização das necessidades em saúde, marcada pelo debate das vulnerabilidades geradas às vidas pelo perfil das regiões e dos serviços no semiárido ou paradigmas de gestão e a urgência de uma ampla política de educação transversal ao trabalho. A vulnerabilidade foi problematizada como acontecimento que não está nos indivíduos, mas provocado pelos preconceitos, incapacidade de escuta e perspectiva moral das instituições e das políticas, além da histórica concentração de renda, riquezas, água e terra ${ }^{11}$. A educação foi problematizada como articulação de ações com expansão da formação para introduzir e consolidar outros olhares para o cuidado, indivíduos e populações, construção de outras aprendizagens sobre o acolhimento em rede. A noção de atualização serviu à indicação dos estudos feministas, queer e trans, virilidade nociva (masculinidade tóxica), população de rua e redução de danos. Um ponto marcante foi a enunciação, em todas as regiões, relativa às práticas integrativas e complementares de cuidado em saúde; a integração das ações de saúde com ações de arte, cultura e educação; e a inserção da educação popular em saúde na agenda da atenção integral (aspectos fora da racionalidade médica hegemônica). Esses temas não estavam presentes antes da primeira rodada regional e ganharam densa expressão na segunda rodada.

Uma sumarização do Plano aponta, então, seis eixos finais: o Eixo um, com seis objetivos e 18 metas; o Eixo dois, com seis objetivos e 21 metas; o Eixo três, com nove objetivos e 26 metas; o Eixo quatro, com seis objetivos e 13 metas; o Eixo cinco, com seis objetivos e 17 metas; e o Eixo seis, com 13 objetivos e 45 metas.

Eixo 1 - Construção e consolidação do Sistema de Saúde Escola: EPS como política de educação e desenvolvimento dos trabalhadores da área. Formulou a construção e consolidação da rede de atenção - assim como seus órgãos ou instâncias de gestão e controle social - em comunidades de aprendizagem/coletivos aprendentes, locais onde se aprende e se ensina em serviço, recebendo estudantes e profissionais em formação e colocandose em contínuo processo de desenvolvimento do trabalho e dos trabalhadores. As propostas contribuíam para instaurar núcleos ou articulações de educação permanente nos serviços, no âmbito de gestão municipal e na instância regional do gestor estadual da saúde.

Eixo 2 - Incentivo ao desenvolvimento científico e tecnológico: os processos de acesso e geração de informação guardam relações de correspondência; assim, os trabalhadores devem ter acesso on-line e ativo ao conhecimento em ferramentas como Estação BVS, Rede BiblioSUS, Telessaúde, Comunidades de Prática e Comunidades de Aprendizagem, como também produzir e divulgar o conhecimento originado de suas ações e seus desafios locais. Foi enunciada a proposta de um sistema repositório da informação científica e tecnológica; centros de documentação por regiões e/ou em municípios; processos de gerenciamento de bibliotecas em saúde; análise das necessidades de formação científica e o fortalecimento das Escolas do SUS no estado, apoio à manutenção e reforma de infraestrutura da rede educacional do SUS e estratégias de acompanhamento de egressos da formação em cursos promovidos pelo SUS.

Eixo 3 - Contribuição às inovações metodológicas de educação na saúde: responder aos desafios metodológicos (os modos de fazer), valorizar as inovações locais e transformá-las em metodologias de educação a fim de que possam ser compartilhadas ou transferidas em programas 
de cooperação intergestores no estado e na região Nordeste, assim como programas de caráter nacional e internacional. 0 debate das inovações metodológicas apareceu referido ao ensino e formação. A defesa foi de um sistema democrático e sustentável dirigido aos estudantes e aos recémformados, além dos servidores dos sistemas de saúde. Evidenciou-se grande valorização das residências integradas em saúde, das vivências e estágios na realidade do SUS, dos programas de bolsas para estudantes de graduação e para a incorporação do desenvolvimento tecnológico com especialistas, mestres e doutores. Destacou-se o desenho de um conjunto de ações para apoiar o provimento de profissionais de Atenção Básica e de Atenção Psicossocial por meio da Ação Educativa e Integração Ensino-Serviço.

Eixo 4 - Participação no desenvolvimento de gestores e lideranças no SUS: captar e capacitar gestores e lideranças de modo a gerar e qualificar pessoas que pudessem assumir quadros de gestão e/ou de controle social em saúde, assim como assessorias parlamentares e representantes de movimentos sociais. Para cumprir os desígnios do SUS há necessidades de bons gestores, o que não significa carreira, mas desenvolvimento de competências de gestão. Igualmente, há necessidade de desenvolver lideranças, fortalecendo o controle social e preparando possiveis quadros para os conselhos de saúde, postos de administração em políticas, serviços e sistemas. Evidenciou-se a proposta de que uma política de educação também seja permanente na direção da gestão e da participação popular, não apenas para a clínica ou saúde na comunidade/no bairro, até mesmo a formação sobre políticas de saúde para assessores parlamentares e membros do sistema judiciário, tendo em vista a defesa do SUS nas ações legislativas e jurídicas.

Eixo 5 - Fortalecimento da integração ensino-serviço na saúde: incentivo e regulação às interações educativas na rede de saúde, estabelecendo relações de troca e colaborativas entre gestores do SUS e instituições formadoras de nível superior ou de nível técnico. Esse eixo apresentou a consolidação de práticas educativas que facilitariam 0 processo de formação profissional na área da saúde, em consonância com as diretrizes do SUS. Os objetivos do eixo incluíram o planejamento e avaliação continuados e participativos em EPS de forma ascendente; o fortalecimento e alinhamento organizacional e político-institucional das CIES; o fortalecimento e a capilarização da Regulação das Práticas de Ensino na Saúde nos municípios; e o maior compromisso social das Instituições de Ensino Superior e Técnico com o SUS. Foram defendidos espaços de trabalho permeados por dimensões da educação, que se tornariam mais acolhedores de estudantes, abrindo espaços para ligas acadêmicas e propostas de pesquisa-intervenção e extensão inovadora. A ideia foi a de criar condições favoráveis para a experimentação de formas inovadoras de interação universidade-sociedade no âmbito do ensino, da pesquisa, da extensão e da formação interprofissional, nelas inserindo chance real de desenvolvimento institucional do SUS e chances de ações que resultassem em uma educação na saúde mais contextualizada nas demandas atuais do sistema, mais inclusiva e geradora de autonomia.

Eixo 6 - Desenvolvimento e aperfeiçoamento da Atenção Integral à Saúde: qualificar a atenção à saúde, ouvidas as áreas técnicas ou programáticas, aperfeiçoando padrões de interpretação e de intervenção no processo saúde-doença e a abordagem clínica no diagnóstico e tratamento. Sob o princípio da integralidade, desponta a promoção de serviços para atender às necessidades da população quanto à promoção e manutenção da saúde, prevenção e tratamento de doenças e agravos, reabilitação, redução de danos e cuidados paliativos, tudo isso envolto à responsabilidade de prestar serviços de elevada qualidade e resolutividade, identificar adequadamente as necessidades biológicas, psicológicas, ambientais e sociais que causam doenças, além de gerenciar as várias tecnologias de atendimento e gerenciamento necessárias para esses propósitos, o que amplia a autonomia humana e protege a saúde. Para tanto, os conceitos de território em saúde, gestão da clínica e rede de atenção coordenada pela atenção básica.

\section{CONCLUSÃO}

Olhar para esse processo nos fez ver a construção de um sistema de saúde em rede que, dentre seus principais desafios, procura tornar a rede de saúde uma rede de ensino e aprendizagem ${ }^{30}$. É no cotidiano, na lida diária, que trabalhadores e usuários descobrem e inventam formas de trabalho e luta, convivendo com o outro e apreendendo de 
modo sensivel as necessidades sociais em saúde ${ }^{27}$. Organizar um serviço que opere segundo a lógica do território, com uma saúde cabra da peste, requer adesão do trabalhador aos projetos de vida que ali se movem. Uma territorialização assim consistente demanda um processo de permanente aprendizagem local ou com os recursos locais existentes e, ao mesmo tempo, capacidade de ativar redes com tais características e tais recursos.

Como foi aprendido na pesquisa-formação, há necessidade de entrelaçamento com grupos de educação popular, de artesania, de arte de rua e com movimentos e práticas da cultura para potencializar a participação social, o desenvolvimento da autonomia dos usuários e as ações de afirmação das singularidades em todos os pontos da rede. A imagem da saúde do cuidado em família orienta a necessidade da colaboração interprofissional e da criação de porosidades entre as ações e os serviços de saúde com os recursos locais ou locorregionais. 0 espaço geográfico em escala local ou dimensão pontual passou à dimensão de lugar, manifestando uma expressão da existência que se apresenta por meio de um cotidiano compartido entre as mais diversas pessoas, instituições, setores e conexões sociais e políticas.

0 lugar é a manifestação local das relações com o mundo ou com o global. o local é território vivido e de invenção da existência, implica as necessidades existenciais e as mobilidades afetivas e sociotécnicas, as interações com os objetos e com as pessoas, a nossa corporeidade e o nosso estar em um mundo em coexistência (visão de mundo vivido local-global). 0 lugar expressa relações verticais, resultado do poder hegemônico, e relações horizontais, resultado de coexistência e resistência. Uma saúde do lugar requer redes de atenção, práticas interprofissionais e visão de sistema integrada ao desenvolvimento do trabalho e dos trabalhadores.

A EPS se mostrou como ação vital se os trabalhadores reordenam suas inserções, redesenham a história e reconfiguram a si mesmos, suas equipes, seus ambientes de trabalho e as relações dos ambientes de trabalho para com seus usuários. A construção de saberes de equipe e a produção de saberes no trabalho auxiliam na constituição da própria formação profissional. A EPS comparece como conhecimento e como mediação com a pluralidade. Sendo assim, convoca sempre ao debate de normas, valores, regras e estilos do trabalho, da gestão, da participação e do desenvolvimento institucional. Na saúde, a permanente educação torna consistente a territorialização, permitindo a expressão de maior efetividade do trabalho e de melhor saúde às pessoas e coletividades. A pesquisa-formação levou significativas contribuições para pensar o encontro entre educação (um processo micropolítico) e a gestão do sistema de saúde (um processo normativo). 0 planejamento apareceu exposto ao inesperado, ao diferente e ao plural de uma "saúde do/no lugar" ou, melhor dito, de uma "saúde cabra da peste", que existe e resiste.

\section{CONTRIBUIÇÃO DOS AUTORES}

Ricardo Burg Ceccim contribuiu com 0 delineamento dos estudos de base, a realização da pesquisa e a redação do manuscrito. Sílvia Maria Negreiros Bomfim Silva contribuiu com o delineamento da pesquisa e a revisão crítica do manuscrito. Luís Fernando de Souza Benício, Kilvia Paula Soares Macedo, Cândido Sampaio de Castro Neto e Karina Oliveira de Mesquita contribuíram com o delineamento e a realização da pesquisa e com a redação do manuscrito. José Luís Paiva de Mendonça Ferreira e Ívina Maria Siqueira Lima contribuíram com a realização da pesquisa e a redação do manuscrito.

\section{REFERÊNCIAS}

1. Brasil. Portaria GM $n^{\circ}$ 3.194, de 28 de novembro de 2017. Dispõe sobre o Programa para o Fortalecimento das Práticas de Educação Permanente em Saúde no Sistema Único de Saúde - Pró-EPS/SUS. Diário Oficial da União [document on the internet]. 30 de novembro de 2017 [cited 2018 Jan 28]; Seção 1:141. Available from: https://www.in.gov.br/materia/-/asset publisher/Kujrw0TZC2Mb/content/id/574490/do12017-11-30-portaria-n-3-194-de-28-de-novembrode-2017-574486

2. Brasil. Manual Técnico 2018 - Programa para o Fortalecimento das Práticas de Educação Permanente em Saúde no SUS - Pró-EPS/SUS. Brasília (DF): Ministério da Saúde; 2018.

3. L'Abbate S. Análise institucional e intervenção: breve referência à gênese social e histórica de uma articulação e sua aplicação na Saúde Coletiva. Mnemosine [serial on the internet]. 2012 [cited 2018 Apr 10];8(1):194-219. Available from: https://www.epublicacoes.uerj. br/index.php/mnemosine/article/view/41580 
4. Parente JRF. Planejamento participativo em saúde. Sanare (Sobral, Online) [serial on the internet]. 2011 [cited 2019 Apr 10];10(1):5461. Available from: https://sanare.emnuvens.c om.br/sanare/article/view/144

5. Ceccim RB, Müller GS, Maia LP, Cataluña RV. Círculos em rede: da construção metodológica à investigação em saúde como pesquisa-formação. Fórum Sociológico. 2014;2(24):104-12. doi: https://doi.org/10.4000/sociologico.1111

6. Veloso MM, Bonilla MH. 0 jornal de pesquisa e o diário de campo como dispositivos da pesquisa-formação. $\quad$ EDU. 2017;6(1):47-58. doi: $\quad$ https://doi.org/10.17564/2316-3828. 2017v6n1p47-58

7. Lemos FC, Galindo D, Reis LP, Moreira MM, Borges AG. Análise documental: algumas pistas de pesquisa em psicologia e história. Psicol estud (Maringá) [serial on the internet]. 2015 [cited 2019 Mar 20];20(3):461-69. Available from: https://periodicos.uem.br/ojs /index.php/PsicolEstud/article/view/27417

8. Viana AL, Dal Poz MR. A reforma do sistema de saúde no Brasil e o programa de saúde da família. Physis. 2005;15(supl):225-64. doi: https://doi.org/10.1590/S0103-73311998000 200002

9. Melo EA, Mendonça MHM, Oliveira JR, Andrade GCL. Mudanças na Política Nacional de Atenção Básica: entre retrocessos e desafios. Saúde debate. 2018;42(esp.1):38-51. doi: https://doi. org/10.1590/0103-11042018s103

10. Santos M. 0 lugar: encontrando o futuro. Rua [serial on the internet]. 1996 [cited $2019 \mathrm{Apr}$ 10];4(1):34-39. Available from: https://periodicos. ufba.br/index.php/rua/article/view/3113

11. Coutinho MJ, Carneiro MS, Edvan RL, Pinto AP. A pecuária como atividade estabilizadora no semiárido brasileiro. Vet zootec [serial on the internet]. 2013 [cited 2019 Apr 10];20(3):434-41. Available from: https://www. fundaj.gov.br/images/stories/observafundaj $\angle a-p e c u a r i a-c o m o-a t i v i d a d e-e s t a b i l i z a d o r a-n o-$ semiarido-brasileiro.pdf

12. Assaré P. Antologia poética. 5. ed. Fortaleza: Demócrito Rocha; 2007.

13. Ceará. Plano Cearense Educação Permanente em Saúde: construção e modelagem da formação e desenvolvimento de pessoal para o SUS [document on the internet]. Fortaleza: Secretaria da Saúde do Estado do Ceará; 2018 [cited 2019 Apr 10]. Available from: https://www.saude. ce.gov.br/wp-content/uploads/sites/9/2018/06/
PLAN O-CEARENSE-DE-EDUCA $\%$ C $3 \% 87 \%$ C $3 \% 830-$ PERMANENTE-EM-SA\%C3\%9ADE-19dez2018-DIGITALilovepdf-compressed.pdf

14. Giovanella L. Planejamento estratégico em saúde: uma discussão da abordagem de Mário Testa. Cad Saúde Pública. 1990;6(2):129-53. doi: https:// doi.org/10.1590/S0102-311X1990000200003

15. Rodrigues E. Dos estilhaços de uma pesquisa. Interface (Botucatu). 2017;21(61):469-80. doi: https://doi.org/10.1590/1807-57622016.0186

16. Brasil. Portaria GM $n^{\circ} 4.279$, de 30 de dezembro de 2010. Estabelece diretrizes para a organização da Rede de Atenção à Saúde no âmbito do Sistema Único de Saúde. Diário Oficial da União [document on the internet]. 06 de outubro de 2011 [cited 2018 May 28]; Seção 1:88. Available from: https://conselho.saude.gov.br/ ultimas noticias/2011/img/07 jan portaria427 g $301210 . p d f$

17. Brasil. Decreto 7.508, de 28 de junho de 2011. Regulamenta a Lei $\mathrm{n}^{\circ} 8.080$, de 19 de setembro de 1990, para dispor sobre a organização do Sistema Único de Saúde, o planejamento da saúde, a assistência à saúde e a articulação interfederativa, e dá outras providências. Diário Oficial da União [document on the internet]. 29 de junho de 2011 [cited 2018 Jun 02]; Seção 1:1. Available from: https://legislacao.presidencia. gov.br/atos/?tipo=DEC\&numero $=7508 \&$ ano $=2011 \&$ ato $=16 \mathrm{fgXUE9UMVpWT875}$

18. Santos LM, Ceccim RB. Educação do/no trabalho no caso da saúde: micropolítica e o componente imaterial da "educo(trans)formação". In: Fernandes RMC, organizadora. Educação no/do trabalho no âmbito das políticas sociais. Porto Alegre: Editora da UFRGS; 2019. p. 119-136.

19. Viana ALD, Iozzi FL, Albuquerque MV, Bousquat A. Saúde, desenvolvimento e inovação tecnológica: nova perspectiva de abordagem e de investigação. Lua Nova. 2011;28(83):41-77. doi: https://doi. org/10.1590/S0102-64452011000200003

20. Ceccim RB. Emergência de um "campo de ação estratégica": ordenamento da formação e educação permanente em saúde. Sanare (Sobral, Online) [serial on the internet]. 2019 [cited 2019 Dec 10];18(1):68-80. Available from: https://sanare.emnuvens.com.br/sanare/article/ view/1307

21. Souza FL, Ponte MA, Linhares AK, Cavalcante NA, Dias MSA, Soares C, et al. A política municipal de educação permanente em Sobral/ CE. Sanare (Sobral, Online) [serial on the internet]. 2008 [cited 2019 Apr 10];7(2)1422. Available from: https://sanare.emnuve ns.com.br/sanare/article/view/27 
22. Ceará. Nota técnica conjunta, de $1^{\circ}$ de dezembro de 2017. Adesão a Portaria 3.194, de 28 de novembro de 2017, que dispõe sobre o Pró-EPS/SUS [document on the internet]. Fortaleza: Secretaria de Saúde do Ceará; 2017 [cited 2021 Apr 10]. Available from: https://www.cosemsce.org.br/documentos/ notastecnicas/notatecnicaconjuntaproepssus.pdf

23. Ceará. Comissão Intergestores Bipartite. Resolução no 188, de 14 de dezembro de 2018. Fortaleza: Secretaria de Saúde do Ceará [document on the internet]; 2018 [cited 2019 Apr 10]. Available from: https://www.saude.ce.gov.br/ wp-content/uploads/sites/9/2018/06/resoluca o 188 2018.pdf

24. Paiva GM, Pedroza AS, Ribeiro MA, Vasconcelos MI, Albuquerque IM, Linhares MS. Estudo bibliométrico acerca da política nacional de educação permanente em saúde. Sanare (Sobral, Online) [serial on the internet]. 2015 [cited 2019 Apr 10];14(2):141-47. Available from: https:// sanare.emnuvens.com.br/sanare/article/view/839

25. Rosa WAG, Labate RC. Programa saúde da família: a construção de um novo modelo de assistência. Rev Latino-am Enfermagem. 2005;13(6):1027-34. doi: https://doi.org/ 10.1590/S0104-11692005000600016

26. Aguiar FAR, Souza TC, Branco JG0, Costa FBC, Torres ARA. Produção do cuidado na rede de atenção ao câncer de mama: revisão integrativa. Sanare (Sobral, Online) [serial on the internet]. 2018 [cited 2019 Apr 16];17(1):84-92. Available from: https://sanare .emnuvens.com.br/sanare/article/view/1226

27. Batista VCL, Ribeiro LCC, Ribeiro CDA, Paula FA, Araújo A. Avaliação dos atributos da atenção primária à saúde segundo os profissionais de saúde da família. Sanare (Sobral, Online) [serial on the internet]. 2016 [cited 2019 Apr 12];15(2):87-93. Available from: https://sanare.emnuvens.com.br/ sanare/article/view/1042

28. Brasil. Portaria GM n ${ }^{0} 2.206$, de 14 de setembro de 2011. Institui, no âmbito da Política Nacional de Atenção Básica, o Programa de Requalificação de Unidades Básicas de Saúde e o respectivo Componente Reforma. Diário Oficial da União [document on the internet]. 19 de setembro de 2011 [cited 2021 Jan 28]; Seção 1:50. Available from: http://bvsms .saude.gov.br/bvs/saudelegis/gm/2011/ prt2206 14 09 2011.html

29. Santos M. Da totalidade ao lugar. São Paulo: Edusp; 2005.

30. Soares CHA. Sistema Saúde Escola de Sobral/ CE. Sanare (Sobral, Online) [serial on the internet]. 2008 [cited 2019 Apr 17];7(2):7-13. Available from: https://sanare.emnuvens.com. $\mathrm{br} / \mathrm{sanare} / \mathrm{article} / \mathrm{view} / 26 / 21$
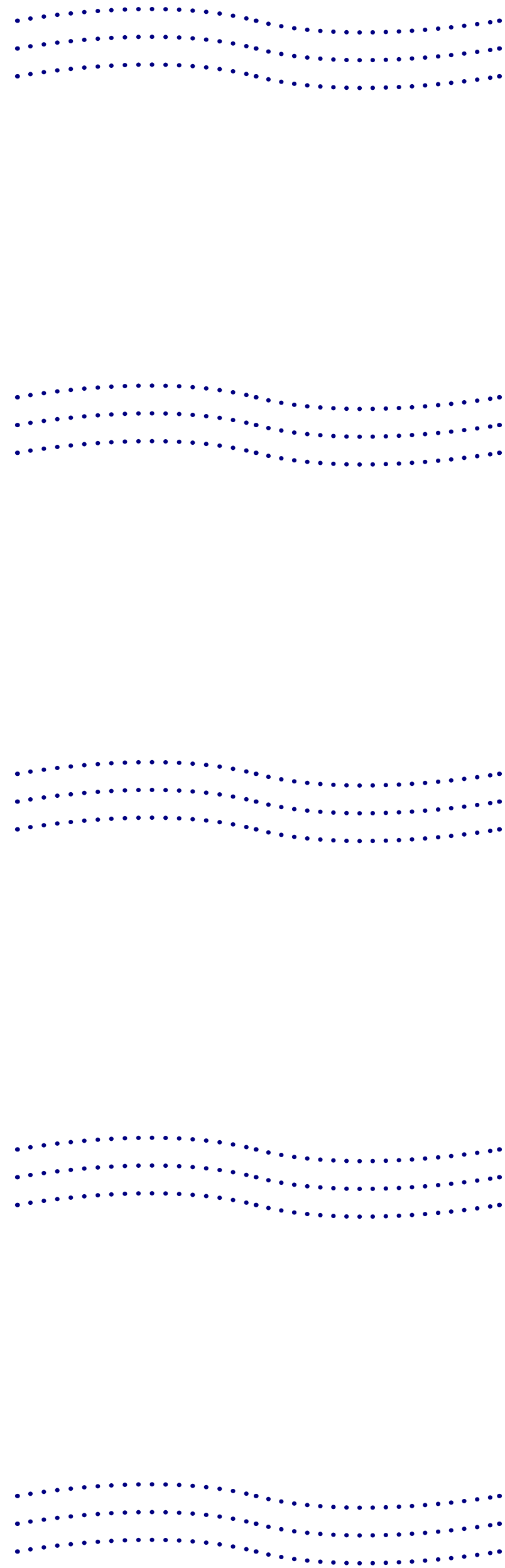